\section{Estudo \\ Ecidebate}

em Testão

Plamejamento
Revista Estudo \& Debate, Lajeado, v. 24, n. 1, 2017. ISSN 1983-036X

DOI: http://dx.doi.org/10.22410/issn.1983-036X.v24i1a2017.1156

\title{
PERCEPÇÃO, CONHECIMENTO E HÁBITOS DE COMPRA DE PRODUTOS GOURMET DA MARCA DO DISTRIBUIDOR: O CASO DE BRAGANÇA, PORTUGAL ${ }^{1}$
}

\author{
Maria Isabel Barreiro Ribeiro², António José Gonçalves Fernandes³ \\ Francisco José Lopes de Sousa Diniz ${ }^{4}$
}

\begin{abstract}
Resumo: Produtos gourmet são produtos de alta qualidade com origem e características específicas, produzidos em pequenas quantidades com matérias-primas de qualidade, utilizando processos de produção diferenciados. Este estudo visa analisar a percepçáo, o conhecimento e os hábitos de compra de produtos gourmet de marca branca na cidade de Bragança, Portugal. Para o efeito, desenvolveu-se um estudo quantitativo, transversal, observacional e descritivo baseado numa amostra acidental constituída por 1.101 indivíduos que foram inquiridos através de um questionário de autopreenchimento. A recolha de dados decorreu durante o mês de junho de 2014 em lojas do sector da distribuição localizadas na cidade de Bragança. Os dados foram editados e tratados com o SPSS 22.0 (Statistical Package for Social Sciences). Calcularam-se estatísticas descritivas, nomeadamente, frequências absolutas e relativas. Segundo os consumidores, os produtos gourmet são produtos de qualidade feitos com bons ingredientes e, por conseguinte, são produtos caros e requintados. A maioria dos inquiridos $(60,0 \%)$ tinha comprado um produto gourmet no ano anterior à pesquisa, num hipermercado $(93,1 \%)$. No entanto, os consumidores compraram produtos gourmet com pouca frequência, menos de uma vez por mês $(28,7 \%)$. Os produtos gourmet adquiridos eram, maioritariamente, da marca do distribuidor $(86,8 \%)$. A marca Gourmet Continente $(84,8 \%)$ revelou ser a marca mais conhecida. Apesar disso, apenas $60,9 \%$ tinha comprado produtos dessa marca. Os resultados sugerem que a cultura gourmet está presente no quotidiano dos consumidores brigantinos. No entanto, estes consumidores compram produtos gourmet com a marca do distribuidor o que lhes permite adquirir produtos de alta qualidade ao menor preço possível.
\end{abstract}

Palavras-chave: Consumidor. Produtos gourmet. Marca do distribuidor. Bragança. Portugal.

1 Este trabalho foi apresentado nas XVII Jornadas Luso-Espanholas de Economia Empresa. Universidade da Beira Interior, Covilhã, 5 e 6 de novembro 2015, Portugal.

2 Instituto Politécnico de Bragança - Escola Superior Agrária, Bragança. Universidade de Trás-os-Montes e Alto Douro - Centro de Estudos Transdisciplinares para o Desenvolvimento, Vila Real. xilote@ipb.pt

3 Instituto Politécnico de Bragança - Escola Superior Agrária, Bragança. Universidade de Trás-os-Montes e Alto Douro - Centro de Estudos Transdisciplinares para o Desenvolvimento, Vila Real. toze@ipb.pt

4 Universidade de Trás-os-Montes e Alto Douro - Centro de Estudos Transdisciplinares para o Desenvolvimento, Vila Real. fdiniz@utad.pt 


\title{
PERCEPTION, KNOWLEDGE AND BUYING HABITS OF DISTRIBUTOR BRAND GOURMET PRODUCTS: THE CASE OF BRAGANÇA, PORTUGAL
}

\begin{abstract}
Gourmet products are high quality products with origin and specific characteristics, produced in small quantities with quality raw materials, using different production processes. This study aims to analyze the perception, knowledge and buying habits of gourmet products with distributor brand in Bragança city, Portugal. To this end, a quantitative, cross-sectional, observational and descriptive study was developed. This research based on a random sample of 1,101 individuals. These individuals surveyed through a self-report questionnaire. Data collection took place during June 2014 in the distribution sector stores located in Bragança city. The data edited and processed with SPSS 22.0 (Statistical Package for Social Sciences). Statistical treatment involved the calculation of descriptive statistics, namely, absolute and relative frequencies. According to surveyed consumers, gourmet products are quality products made with good ingredients and, therefore, are expensive and exquisite products. Most respondents (60.0\%) bought a gourmet product in the year prior the survey in a hypermarket (93.1\%). However, consumers of gourmet products bought this type of products less than once per month (28.7\%). Most consumers (86.8 \%) bought gourmet products with distributor brand. The Gourmet Continente brand $(84.8 \%)$ proved to be the best-known brand. However, only $60.9 \%$ bought products with that brand. The results suggest that gourmet culture is present in the daily lives of Bragança city consumers. However, these consumers aren't willing to pay so much more for a high quality product. In fact, these urban consumers are buying gourmet products with distributor brand in order to purchase high quality products at the lowest price possible. This trend can be seen as an opportunity to rural producers because they know how to produce high quality products but they don't know how to sell. So, this marketing strategy could ensure sales at a premium price. This way, added value is generated and retained in rural areas.
\end{abstract}

Keywords: Consumer. Gourmet products. Distributor brand. Bragança. Portugal.

\section{INTRODUÇÁO}

A procura de produtos gourmet tem vindo a aumentar seja pela crescente tendência de estilos de vida do consumidor ligados ao mundo do distinto e do exclusivo, seja pela curiosidade pelo que é novo e diferente (PAULINO; RIBEIRO, 2011). Segundo estas investigadoras, o conceito gourmet engloba produtos de qualidade superior, que apresentam características raras e distinguíveis dos demais, que se enquadram e projetam num mercado mais exclusivo de consumo e que proporcionam prazer e satisfação pessoal ao consumidor, assim como pode referir-se a uma pessoa que tem o gosto por apreciar iguarias sofisticadas e exclusivas.

Produtos gourmet são produtos de alta qualidade, em geral, certificados com origem específica, características únicas e produzidos em pequenas quantidades (FERNANDES et al., 2015). Trata-se, por isso, de bens de luxo que apelam, especialmente, a consumidores sofisticados com estatuto socioeconómico acima da média. Ora, segundo Barroso e Madureira (2006), ao luxo está associado um preço prémio. Efetivamente, os consumidores estáo dispostos a pagar mais por produtos diferenciados aos quais percecionem qualidade mais elevada.

Assim sendo, considerou-se oportuno analisar a percepção, o conhecimento e os hábitos de compra de produtos gourmet da marca do distribuidor na cidade de Bragança, Portugal. Para o efeito, levou-se a cabo um estudo quantitativo, transversal, observacional e 
descritivo. Foi recolhida uma amostra acidental constituída por 1.101 indivíduos que foram inquiridos em retalhistas e distribuidores a operar no concelho de Bragança.

Os dados foram recolhidos com recurso a um questionário administrado diretamente aos consumidores brigantinos durante o mês de junho de 2014. Posteriormente, foram editados e tratados no SPSS 22.0 (Statistical Package for Social Sciences) de forma a calcular frequências absolutas e relativas.

A estrutura do corpo do artigo divide-se em seis secçôes, nomeadamente, introdução, enquadramento teórico e contextualização, principais objetivos e metodologia, resultados, conclusóes e, finalmente, a bibliografia. $\mathrm{Na}$ segunda secção, faz-se a revisão da literatura de forma a enquadrar, teoricamente, o tema em estudo. A terceira secção diz respeito à metodologia usada para levar a cabo esta investigação, designadamente, objetivos, população, amostra, instrumento de recolha de dados e procedimentos a adotar no tratamento dos dados. Posteriormente, na quarta e quinta seções, apresentam-se os resultados e as conclusôes, respectivamente. E, finalmente, na sexta secção, apresentam-se as referências bibliográficas.

\section{ENQUADRAMENTO TEÓRICO E CONTEXTUALIZAÇÃO}

Cada vez mais, as marcas são ativos muito relevantes para as empresas. Economicamente, a marca facilita as transaçôes, pois torna mais rápida a interpretação e o processamento das informaçóes pelo cliente em relação ao produto, ativa as suas expectativas de confiança e identificação na decisão de compra (ELIAS; BATAGIN; MORAES, 2012). A marca, sempre foi um meio eficaz de sintetizar e comunicar uma realidade complexa, numa imagem que transcende fronteiras (FREITAS, 2010). São vários os principais objetivos para o uso de marcas de produtos alimentares, nomeadamente, atribuir um nome que permita a sua diferenciação dos concorrentes; facilitar a identificação do produto entre os produtos concorrentes; tornar o produto apelativo, com base numa comunicação criativa; e, assegurar ao consumidor um certo nível de qualidade dos produtos (BARROSO; MADUREIRA, 2005).

Pode dizer-se que a imagem de marca é a percepção que um consumidor tem a propósito de um conjunto de ideias, de sentimentos, de atitudes, de crenças. Ou seja, é uma percepção dos símbolos atribuídos a um produto (identidade da marca) (KAPFERER, 2004). Assim, a imagem de marca está relacionada com a imagem que um indivíduo tem de si mesmo (RUÃO; FARHANGMER, 2000). Por seu lado, percepção é a imagem mental que se forma com a ajuda da experiência e das necessidades. É o resultado de um processo de selecção, interpretação e correcção de sensaçóes.

As marcas do distribuidor, também denominadas de marcas próprias ou marcas brancas, são de propriedade e uso exclusivo de um retalhista, grossista ou distribuidor, que não o produtor. Estas marcas, a partir do próprio nome, permitem ao consumidor identificar a empresa de cadeia de distribuição a que pertencem. Contudo, a sua distribuição e comercialização está limitada a essa loja ou a uma cadeia de lojas (CARDOSO; ALVES, 2008). A marca do distribuidor permite aos produtores canalizarem recursos para a produçáo e dar-lhes alguma garantia de escoamento dos produtos (MELLO; MARREIROS, 2009). Assim, os produtores podem utilizar esta solução e concentrarem-se no que eles sabem 
fazer melhor, ou seja, produzir produtos de alta qualidade. Esta estratégia de marketing pode beneficiar produtores rurais porque, tradicionalmente, estes produtores têm grandes dificuldades no que diz respeito à comercializaçáo dos seus produtos. Além disso, esta estratégia pode ajudar os produtores rurais a aumentar o seu rendimento. De facto, o luxo está associado a um preço premium (BARROSO; MADUREIRA, 2005). Por essa razáo, os consumidores estáo dispostos a pagar mais por determinados produtos caso percecionem um alto nível de qualidade. Em marketing, o luxo é visto como o principal fator de diferenciação de uma marca numa determinada categoria de produto. Na verdade, o consumidor decide sobre a relação qualidade/preço que melhor o serve e para o qual está disposto a pagar uma certa quantia de dinheiro.

Os produtos gourmet são bens de luxo, uma vez que podem definir-se como produtos de alta qualidade que podem ser certificados por entidades externas. Sáo produtos com origem e características específicas, produzidos em pequenas quantidades com matériasprimas de alta qualidade utilizando processos de produçáo diferenciados (RIBEIRO; FERNANDES, 2015a,b). A cultura gourmet está presente no quotidiano dos consumidores urbanos e cria procura. É a tendência crescente de estilos de vida do consumidor ligado a um mundo diferente e exclusivo. Esta tendência, tal como referido anteriormente, pode e deve ter um impacto nas zonas rurais. A produção de produtos gourmet com a marca do distribuidor pode e deve permitir que os agentes rurais gerem maior valor acrescentado e, ao mesmo tempo, resolvam o problema da escassez de recursos financeiros mencionados anteriormente.

Várias cadeias de retalho alimentar a operar em Portugal lançaram produtos gourmet e produtos biológicos com a sua própria marca (marca do distribuidor), designadamente, chocolates, geleias, frutas, legumes, carne, salsichas, leite, queijo, azeite, bolachas, entre outros. Estes produtos destinam-se a clientes que exigem produtos melhores, com melhor qualidade mas que são, ao mesmo tempo, sensíveis ao preço, uma variável decisiva no momento da compra (FERREIRA; REIS; SANTOS, 2011). Na opinião de Cardoso e Alves (2008), na generalidade, os produtos de marca do distribuidor são bem aceites pela maioria dos consumidores sendo a qualidade, para além do preço, um dos fatores determinantes na decisão de compra. Atualmente, os consumidores tendem a aperceber-se da qualidade dos produtos da marca de distribuidor, comprando-os e consumindo-os com frequência, acabando por não estabelecerem grandes diferenças entre as marcas de distribuidor e do produtor. Segundo Freitas (2010), existe uma aproximação evidente entre as marcas do distribuidor e do produtor, não só pelo design, como também por outros atributos que as associam tornando-as cada vez mais comparáveis. Facto que tem preocupado e forçado os fabricantes a repensar as suas estratégias perante os consumidores (KUMAR; STEENKAMP, 2008).

\section{PRINCIPAIS OBJETIVOS E METODOLOGIA}

Este estudo tem como objetivos analisar a percepçáo, o conhecimento e os hábitos de compra de produtos gourmet de marca branca na cidade de Bragança, Portugal. Para atingir estes objetivos, foi desenvolvido um estudo quantitativo, transversal, observacional e descritivo. 
De acordo com Hoppen, Lapointe e Moreau (1996) e Jung (2004), este estudo assume uma natureza transversal, porque a informação foi recolhida apenas uma vez, proporcionando um "fotografia" das variáveis relevantes do estudo em um determinado momento. Uma vez que o estudo se enquadra na área das ciências sociais e tem como objetivo identificar os fatores que contribuem para o consumo de produtos gourmet, de acordo com os mesmos investigadores, pode ser classificado como observacional. Por outro lado, o estudo pode ser classificado como quantitativo, porque permite a representação do conhecimento adquirido na forma de gráficos, diagramas e cálculos. Finalmente, este estudo é descritivo pois envolve apenas o cálculo das estatísticas descritivas.

Para realizar este estudo, foi recolhida uma amostra, não probabilística, acidental constituída por 1.101 indivíduos que foram inquiridos em retalhistas e distribuidores a operar no concelho de Bragança. Em 2011, de acordo com o INE (2012), a populaçáo da cidade de Bragança era constituída por 19.991 habitantes. Assim, pode dizer-se que a amostra recolhida é representativa em termos quantitativos porque incluía muito mais do que $1 \%$ da população da cidade de Bragança. Efetivamente, em estudos de mercado, a amostra é considerada representativa, desde que envolva, pelo menos, $1 \%$ da populaçáo a estudar (KOTLER; ARMSTRONG, 2007). No entanto, estes autores consideram que amostras maiores proporcionam resultados mais credíveis.

Para a recolha dos dados, foi utilizado um questionário adaptado de Nunes (2011). O questionário foi aplicado diretamente aos consumidores da cidade de Bragança, Portugal durante o mês de junho de 2014. O questionário era constituído por duas partes. A primeira continha questóes acerca das características do respondente que viria a permitir definir o perfil dos consumidores de produtos gourmet com a marca do distribuidor. A segunda parte continha perguntas sobre a percepção do consumidor urbano e conhecimento sobre produtos gourmet e hábitos de compra desses produtos. Antes da aplicação do questionário, foi solicitada autorização aos diretores das lojas de distribuição localizadas na cidade de Bragança. O questionário não levava mais de 10 minutos para ser preenchido e não requeria a identificação pessoal o que garantiu o anonimato do inquirido.

Posteriormente, os dados foram tratados com o SPSS 22.0 (Statistical Package for Social Sciences). Como se trata de um estudo descritivo, o tratamento de dados estatísticos envolveu o uso de estatística descritiva, ou seja, o cálculo de frequências absolutas e relativas para as variáveis de natureza nominal ou ordinal e medidas de tendência central (média) e de dispersão (desvio-padrão) para as variáveis de natureza quantitativa (MAROCO, 2007; PESTANA; GAGEIRO, 2002).

De uma amostra global, constituída por 1.101 inquiridos, 59,2\% eram do género feminino e $40,8 \%$ do género masculino (TABELA 1). A idade dos inquiridos estava compreendida entre os 18 e os 96 anos de idade. A idade média registada foi de 36,14 anos com um desvio padrão de 15,786 . 
Tabela 1 - Características dos consumidores

\begin{tabular}{|c|c|c|c|}
\hline \multirow{2}{*}{ Variável } & \multirow{2}{*}{ Categorias } & \multicolumn{2}{|c|}{ Frequências } \\
\hline & & $\mathbf{N}$ & $\%$ \\
\hline \multirow{2}{*}{ Género $(\mathrm{N}=1.101)$} & Masculino & 449 & 40,8 \\
\hline & Feminino & 652 & 59,2 \\
\hline \multirow{3}{*}{ Classes etárias $(\mathrm{N}=1.100)$} & 18 a 24 anos & 320 & 29,1 \\
\hline & 25 a 64 anos & 706 & 64,2 \\
\hline & 65 anos ou mais & 74 & 6,7 \\
\hline \multirow{4}{*}{ Estado civil ( $\mathrm{N}=1096)$} & Solteiro & 512 & 46,7 \\
\hline & Casado/união de facto & 464 & 42,3 \\
\hline & Separado/divorciado & 73 & 6,7 \\
\hline & Viúvo & 47 & 4,3 \\
\hline
\end{tabular}

A maioria dos consumidores (64,2\%) tinha entre 25 e 64 anos que, segundo o INE (2012), corresponde à população ativa. Quanto ao estado civil, apenas 1.096 inquiridos responderam a esta questáo. Destes, $46,7 \%$ eram solteiros, $42,3 \%$ eram casados, $6,7 \%$ eram divorciados ou separados e 4,3\% eram viúvos (TABELA 1).

\section{RESULTADOS}

Como pode ver-se na Figura 1, segundo os respondentes, o produto gourmet é um produto de qualidade feito com bons ingredientes $(59,5 \%)$, um produto caro $(52,5 \%) \mathrm{e}$ um produto requintado $(42,7 \%)$. Ou seja, são bens de luxo que apelam, especialmente, a consumidores sofisticados com estatuto socioeconómico acima da média. Resultados similares tinham já sido encontrados por Fernandes et al. (2015), num estudo levado a cabo em Bragança, Portugal. De facto, nesse estudo dedicado ao perfil do consumidor e hábitos de consumo de produtos gourmet, estes investigadores consideravam que produtos gourmet são produtos de alta qualidade, em geral, certificados com origem específica, características únicas e produzidos em pequenas quantidades.

Outras características como a autenticidade (21,2\%), a exclusividade (20,6\%) são características menos importantes quando os consumidores pensam em produtos gourmet. Apenas $15,3 \%$ dos inquiridos associam o produto gourmet a um produto diferenciado e a um produto que resulta de um método de confecção especial. Finalmente, apenas 10,4\% dos inquiridos consideraram que o produto gourmet deve ser artesanal (10,4\%). No entanto, segundo a Oficina Económica y Comercial de la Embajada de España en Nueva York (2010), os produtos mais saudáveis, de rápida preparação e que sejam uma novidade para os sentidos serão aqueles que, no futuro, poderão vir a ter mais oportunidades de sucesso no mercado dos produtos gourmet. 
Figura 1 - Características dos produtos gourmet $(\mathrm{N}=1.101)$

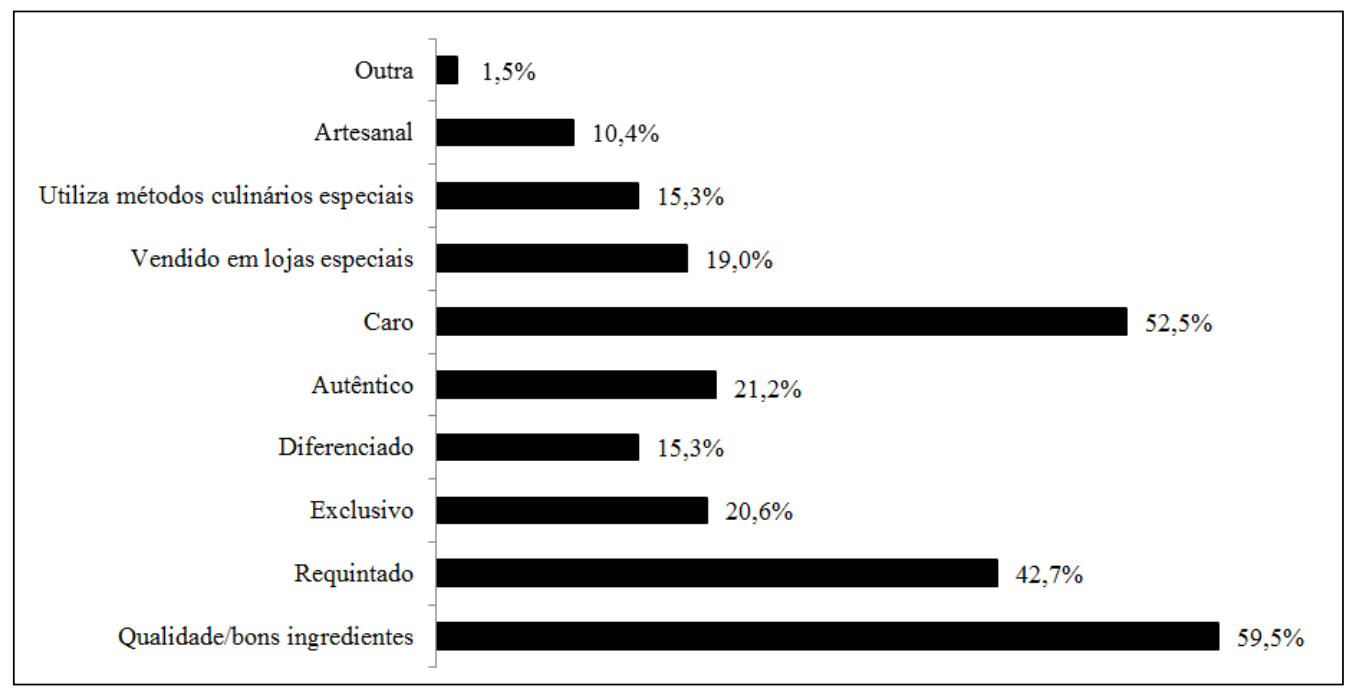

A maioria dos inquiridos (60,0\%) tinha comprado um produto gourmet nos 12 meses anteriores ao inquérito. Para estes, a frequência de compra foi a seguinte: menos de uma vez por mês $(28,7 \%)$, uma vez por mês $(11,4 \%)$, mais do que uma vez por mês $(7,8 \%)$ e $12,1 \%$ afirmaram que não sabiam ou não se lembravam de os ter comprado (FIGURA 2). Por se tratar de um produto caro é natural que, apesar da maioria dos inquiridos ter comprado um produto gourmet no ano anterior á realização do estudo, não o possa fazer frequentemente.

Figura 2 - Frequência da compra de produtos gourmet $(\mathrm{N}=1.101)$

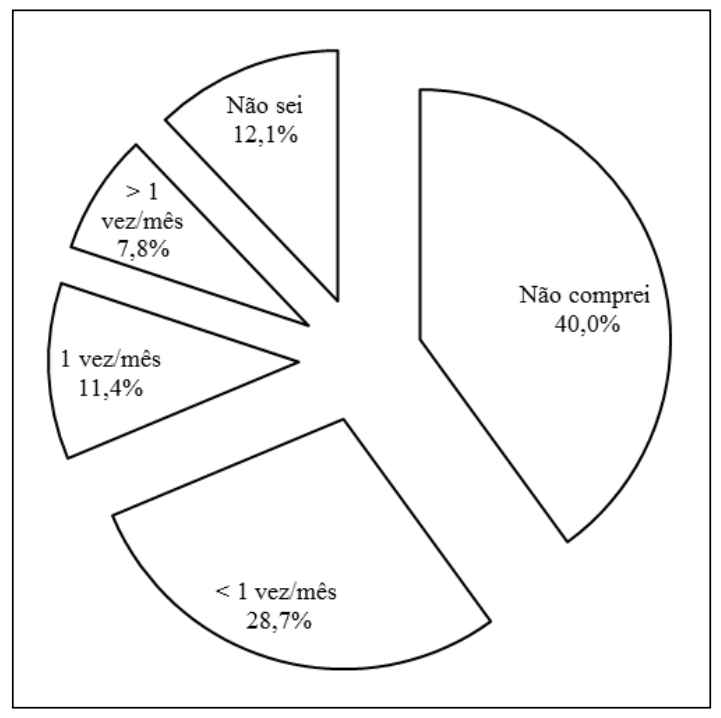

A grande maioria $(93,1 \%)$ adquiriu produtos gourmet no hipermercado, cerca de $21 \%$ em lojas gourmet, $6,4 \%$ no supermercado ou minimercado, $5,8 \%$ na internet, $2,5 \%$ 
na mercearia e $1,5 \%$ não sabiam ou não se lembravam (FIGURA 3). Tal facto não é de surpreendente uma vez que, em Portugal, a distribuição alimentar é caracterizada aumento do peso dos hipermercados e supermercados em detrimento do peso do comércio tradicional. A grande variedade de produtos, os preços mais baixos, as promoçóes e os horários alargados levaram ao sucesso deste tipo de cadeia de distribuição (FERREIRA; REIS; SANTOS, 2011).

Figura 3 - Local da compra de produtos gourmet

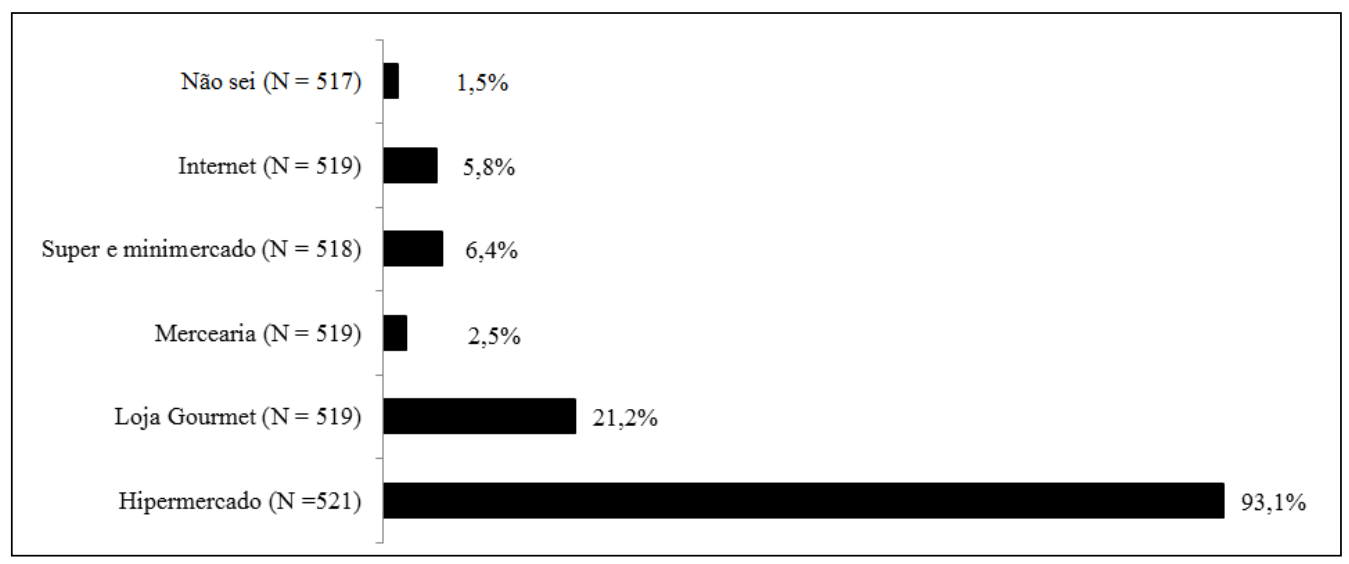

A maioria dos produtos gourmet adquiridos (86,8\%) era da marca do distribuidor, tal como pode ver-se na Figura 4. A este resultado não será alheio o facto dos produtos gourmet da marca do produtor serem mais caros. Verifica-se, pois, que estes consumidores exigem produtos com melhor qualidade mas que, simultaneamente, são sensíveis ao preço, uma das variáveis do marketing-mix que, segundo Ferreira, Reis e Santos (2011), Cardoso e Alves (2008) e Barroso e Madureira (2005), é uma variável decisiva no momento da compra. 
Figura 4 - Produtos gourmet da marca do distribuidor $(\mathrm{N}=479)$

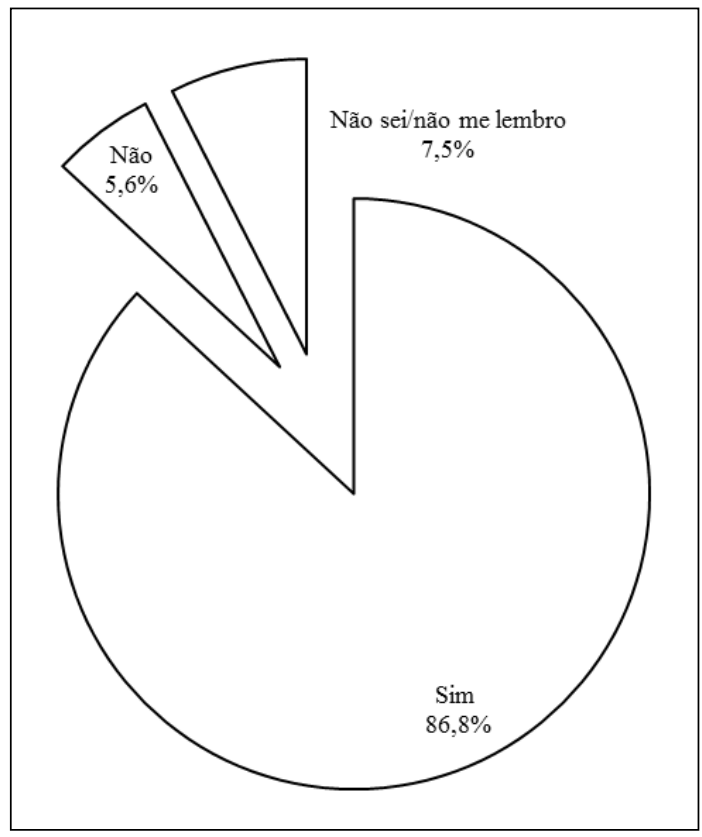

Para além disso, $57,6 \%$ não conheciam a marca Gourmet Auchan, 46,9\% desconheciam a marca Gourmet Intermarché, 35,8\% não conheciam a marca Gourmet Pingo Doce, 20,1\% não conheciam a marca Luxe da distribuidora Lidl e 15,2\% não conheciam a marca Gourmet Continente (FIGURA 5). Os resultados sobre a marca Gourmet Auchan são normais porque o Grupo Auchan não opera na cidade de Bragança. Convém referir que, segundo Ferreira, Reis e Santos (2011), esta cadeia da distribuição portuguesa é a líder de mercado com $21 \%$ da quota de mercado, seguida pelo Grupo Jerónimo Martins (marca Pingo Doce) com 16\%, Intermarché (11\%), Auchan (9\%), Lidl (8\%) e Minipreço (5\%).

A marca Gourmet Continente foi identificada, pelos consumidores, como a marca do distribuidor mais conhecida. De facto, $84,8 \%$ dos inquiridos conheciam essa marca. No entanto, apenas $60,9 \%$ dos inquiridos tinham comprado produtos gourmet com esta marca (FIGURA 5) pois, apesar de se tratar de uma marca do distribuidor, os produtos gourmet acabam sempre por ser mais caros que os outros produtos. 
Figura 5 - Conhecimento e hábitos de compra das marcas dos distribuidores

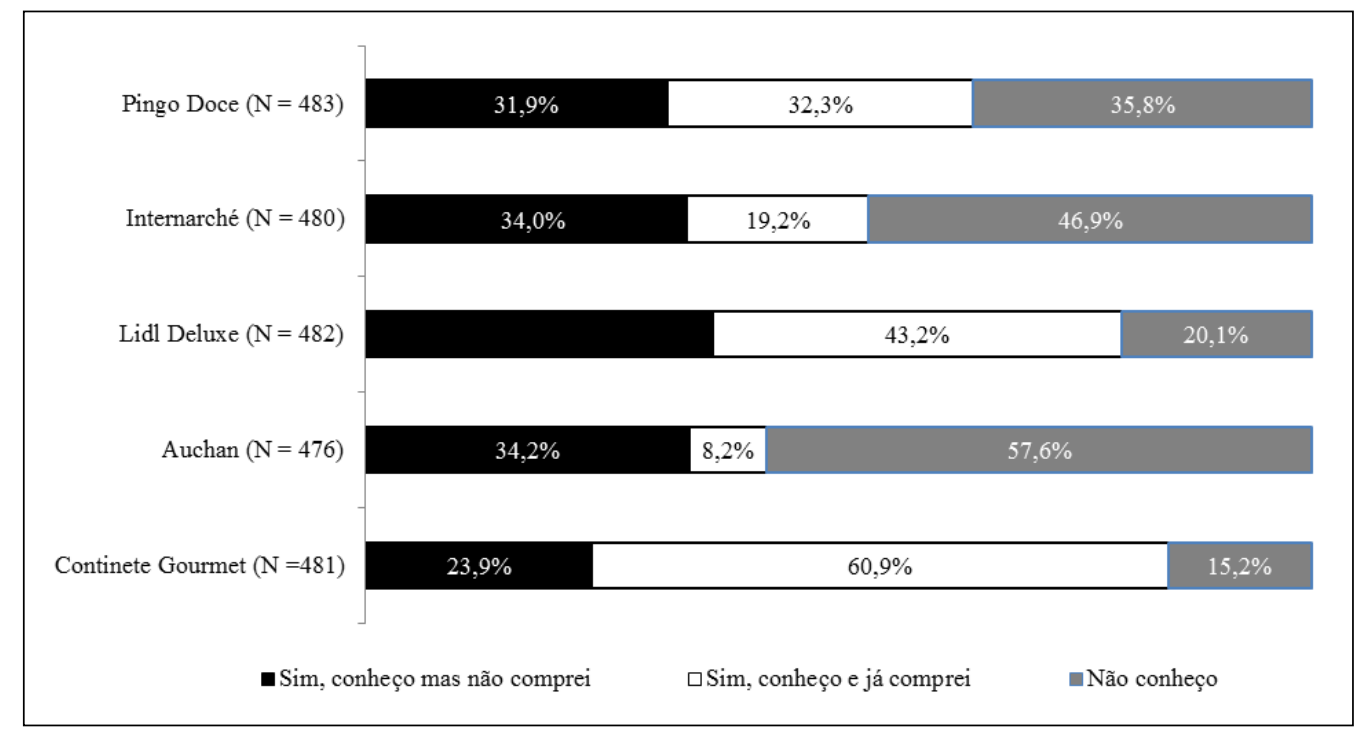

A marca Gourmet Continente é líder em todos os produtos considerados, nomeadamente, produtos congelados $(48,2)$; compotas, geleias e marmeladas $(42,0 \%)$; bolachas $(37,9 \%)$; patés $(35,1 \%)$; e, queijos $(45,6 \%)$, tal como pode ver-se na Figura 6. Segundo Ferreira, Reis e Santos (2011), o lançamento deste tipo de produto por parte das cadeias de retalho a operar em Portugal surgiu na sequência da resposta das cadeias retalhistas às lojas discount. De facto, nesse contexto concorrencial, as cadeias retalhistas aumentaram a oferta de produtos de marca branca e outras marcas de menor visibilidade capazes de competirem com os preços relativamente mais baixos das lojas discount. É, precisamente, nesse contexto que surgem os produtos gourmet e produtos biológicos de marca própria. 
Figura 6 - Aquisição de produtos gourmet com a marca do distribuidor

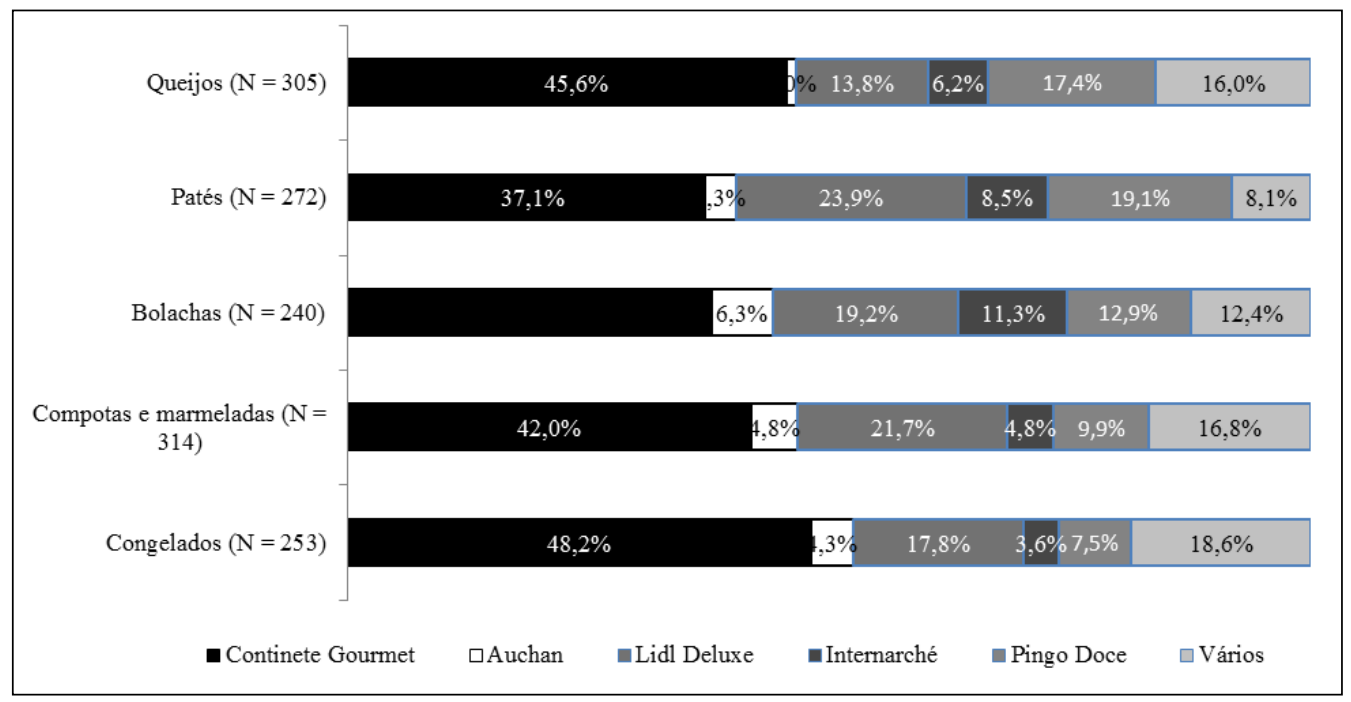

\section{CONCLUSÓES}

Os objetivos deste estudo envolveram a análise da percepçáo, conhecimento e hábitos de compra de produtos gourmet de marca branca pelos consumidores brigantinos. Para atingir estes objetivos, foi recolhida uma amostra acidental constituída por 1.101 indivíduos dos quais $59,2 \%$ eram do sexo feminino e $40,8 \%$ do sexo masculino com idades compreendidas entre os 18 e os 96 anos de idade. A maioria dos inquiridos era solteira $(46,7 \%)$ ou casada $(42,3 \%)$.

Os resultados mostram que, de acordo com os consumidores inquiridos, os produtos gourmet são produtos de qualidade feitos com bons ingredientes e, por conseguinte, são produtos caros e requintados. A maioria dos inquiridos (60,0\%) tinha comprado um produto gourmet no ano anterior à pesquisa num hipermercado $(93,1 \%)$. No entanto, os consumidores compraram produtos gourmet menos de uma vez por mês $(28,7 \%)$. Os produtos gourmet adquiridos foram, principalmente, da marca do distribuidor $(86,8 \%)$. Gourmet Continente foi a principal marca do distribuidor que registou maior reconhecimento. De facto, $84,8 \%$ dos entrevistados conhecia essa marca. No entanto, apenas $60,9 \%$ já tinham comprado produtos Gourmet Continente.

Os resultados sugerem que a cultura gourmet está presente no quotidiano dos consumidores brigantinos. No entanto, estes consumidores não estáo dispostos a pagar muito mais por um produto de alta qualidade. Na verdade, estes consumidores compram produtos gourmet com a marca do distribuidor, de forma a adquirirem produtos de alta qualidade ao menor preço possível. Esta tendência pode ser vista como uma oportunidade para os produtores rurais dado o potencial de crescimento deste tipo de produtos. Efetivamente, os produtores sabem como produzir produtos de alta qualidade, mas náo sabem como os vender, isto é, não sabem valorizar a sua produção. Assim, esta estratégia poderia garantir vendas a um preço premium. Desta forma, o valor acrescentado é gerado e mantido nas zonas rurais. 
Efetivamente, num estudo realizado por Fernandes, Ribeiro, Cabo e Matos (2015) acerca do perfil do consumidor e hábitos de consumo de produtos gourmet na mesma cidade, dos 300 inquiridos, 119 mostraram estar dispostos a pagar mais por produtos gourmet. Destes, $47,1 \%$ estavam dispostos a pagar até $25 \%$ mais e $31,9 \%$ entre 25 a $50 \%$. Tal facto reforça a ideia de que o mercado de produtos gourmet tem um grande potencial de crescimento. Segundo a Oficina Económica y Comercial de la Embajada de Espańa en Nueva York (2010), os produtos locais, sustentáveis e ecológicos são aqueles que se espera virem a ter maior crescimento nos próximos anos. Para além disso, os alimentos biológicos e naturais continuarão a ser fundamentais no mercado dos produtos gourmet.

Uma das limitaçóes deste estudo está relacionada com o facto de se tratar de um estudo transversal e, portanto, de se tratar de um estudo estático. Esta limitação é suscetível de ser superada em investigaçóes futuras que permitam acompanhar a evolução dos hábitos de consumo deste produto.

\section{AGRADECIMENTOS}

Este trabalho é financiado por: Fundos Europeus Estruturais e de Investimento, na sua componente FEDER, através do Programa Operacional Competitividade e Internacionalização (COMPETE 2020) [Projeto no 006971 (UID/SOC/04011)]; e por Fundos Nacionais através da FCT - Fundação para a Ciência e a Tecnologia, no âmbito do projeto UID/SOC/04011/2013.

\section{REFERÊNCIAS:}

BARROSO, M. \& MADUREIRA, T. (2005). Marketing nas pequenas e médias exploraçóes agrícolas. Porto: Sociedade Portuguesa de Inovação.

CARDOSO, A. \& ALVES, P. (2008), Atitude dos consumidores relativamente à marca dos distribuidores. Revista da Faculdade de Ciências Humanas e Sociais - UFP, 5, pp. $38-55$.

ELIAS, J.; BATAGIN, M. \& MORAES, V. (2012). Um estudo exploratório sobre as marcas de luxo como mercado promissor no Brasil. Revista Conteúdo, 2 (1): 64-77.

FERNANDES, A.; RIBEIRO, M.I.; CABO, P. \& MATOS, A. (2015). Perfil do consumidor e hábitos de consumo de produtos gourmet em Bragança, Portugal. I Congresso Nacional das Escolas Superiores Agrárias. Instituto Politécnico de Bragança, 2 e 3 de dezembro.

FERREIRA, M., REIS, M. \& SANTOS, J. (2011). Mudança no sector alimentar: o Pingo Doce. Caso de estudo no 8. GlobADVANTAGE - Centre of Research in International Business \& Strategy. 
FREITAS, D. (2010). Lealdade dos consumidores às marcas de distribuidor. Tese de Mestrado em Gestão Comercial. Faculdade de Economia. Universidade do Porto.

HOPPEN, N, LAPOINTE, L. \& MOREAU, E. (1996). Um guia para avaliação de artigos de pesquisa em Sistemas de Informação. Revista de Administraçáo. 2 (2). 42-46.

INE (2012). Censos 2011. Lisboa: Instituto Nacional de Estatística.

JUNG, C. (2004). Metodologia para pesquisa e desenvolvimento. Rio de Janeiro: Editora Axcel Books do Brasil.

KAPFERER, J. (2004). As marcas, capital da empresa: criar e desenvolver marcas fortes. Porto Alegre: Bookman.

KOTLER, P. \& ARMSTRONG, G. (2007). Princípios de Marketing. São Paulo: Editora Prentice-Hall.

KUMAR, N. \& STEENKAMP, J. (2007), Private Label Strategy, Cambridge, MA: Harvard Business School Press.

MAROCO, J. (2007). Análise Estatística com utilização do SPSS. Lisboa: Edições Sílabo.

MELLO, L. \& MARREIROS, C. (2009). Marketing de Produtos Agrícolas. Lisboa: Associação Nacional de Jovens Agricultores de Portugal.

NUNES, S. (2011). Produtos alimentarem Gourmet: perspetivas do consumidor, do fornecedor e do cozinheiro profissional. Dissertação de Mestrado. Universidade Técnica de Lisboa. Instituto Superior de Economia e Gestão.

OFICINA ECONÓMICA Y COMERCIAL DE LA EMBAJADA DE ESPAÑA EN NUEVA YORK (2010). La distribución de productos gourmet en Estados Unidos. Instituto Espñol de Comércio Exterior.

PAULINO, S. \& RIBEIRO, R. (2011). Estratégias de Comunicação para Nichos de Mercado: As Águas Premium em Portugal. Seminário em Ciências da Comunicação, Instituto Superior de Ciências Sociais e Políticas, Universidade Técnica de Lisboa, Portugal.

PESTANA, M. \& GAGEIRO, J. (2002). Análise de Dados para Ciências Sociais: A complementaridade do SPSS. Lisboa: Edições Sílabo.

RIBEIRO, M. \& FERNANDES, A. (2015a). Perceçáo, conhecimento e hábitos de compra de produtos gourmet de marca branca: $\mathrm{O}$ caso de Bragança, Portugal. XVII Jornadas Luso-Espanholas de Economia Empresa. Universidade da Beira Interior, Covilhã, Portugal. 
RIBEIRO, M. \& FERNANDES, A. (2015b). Perception, knowledge and buying habits of gourmet products by urban consumers from Bragança city, Portugal. International Conference Meanings of the Rural - between social representations, consumptions and rural development strategies. Universidade de Aveiro, Aveiro, Portugal.

RUÁO, T. \& FARHANGMER, M. (2000). A imagem de marca: análise das funçóes de representaçáo e apelo no marketing das marcas. Um estudo de caso. Actas do I Seminário de Marketing Estratégico e Planeamento, Escola de Economia e Gestão, Universidade do Minho. 